\title{
Towards harmonizing competing models: Russian forests' net primary production case study
}

Arkady Kryazhimskiy $\dagger$ Elena Rovenskaya (rovenska@iiasa.ac.at)

Victoria Veshchinskaya (veshchin@iiasa.ac.at)

Mykola Gusti (gusti@iiasa.ac.at)

Dmitry Shchepashchenko (schepd@iiasa.ac.at)

Anatoly Shvidenko (shvidenk@iiasa.ac.at)

\section{Approved by}

Elena Rovenskaya

Program Director, Advanced Systems Analysis

February, 2015 


\section{Contents}

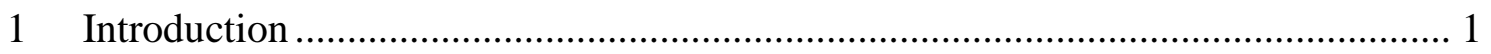

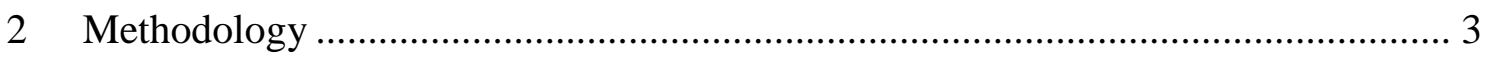

3 Uncertainties in NPP estimates ........................................................................ 5

3.1 NPP estimation methods and associated uncertainties .................................... 5

3.2 The landscape-ecosystem approach ............................................................... 6

3.3 Dynamic global vegetation models .............................................................. 6

3.4 Comparison of DGVMs- and LEA-based forest NPP estimates for Russia ...... 7

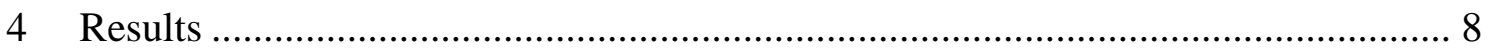

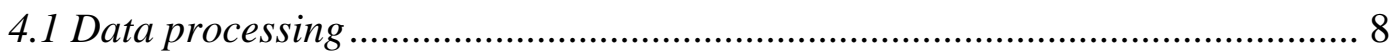

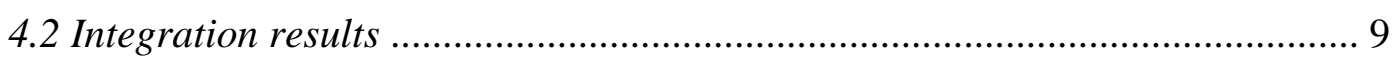

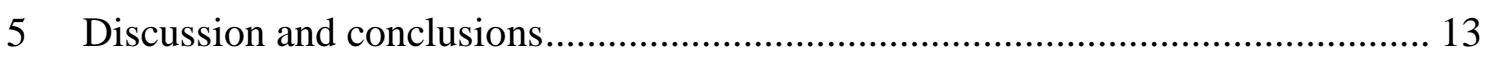

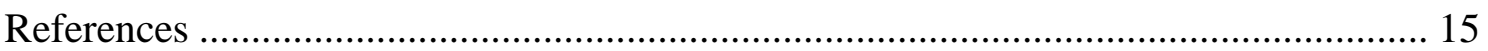




\section{Abstract}

This paper deals with the issue of reconciling competing stochastic estimates provided by independent sources. We employ an integration method based on a principle of mutual compatibility of prior estimates. The method does not take into account credibility of the sources of the estimates, including their past performance. The quality of integration is evaluated in terms of change in the probability distribution. We use the method to integrate two types of estimates of the annual Net Primary Production (NPP) of the forest ecosystems in seven bioclimatic zones in Russia. The estimates are generated based on an empirical landscape-ecosystem approach and on an ensemble of dynamic global vegetation models; the gaps in their estimates reach $23 \%$. Elimination of the gaps may help better quantify the input of the terrestrial ecosystems to the global carbon cycle. The main result of this paper is the evidence of applicability of the method for selection a set of candidates for credible integrated estimates of uncertain ecological parameters (like forest NPP) integrating prior estimates.

Keywords: net primary production of forest, multi-model ensembles, Bayesian approach 


\section{Acknowledgments}

The first and second authors acknowledge DG research for funding through COMPLEX project \#308601, www.complex.ac.uk

Work of the first author was partially supported by the Russian Foundation for Basic Research, projects \#13-01-00685 and \#13-01-12446 ofi_m2. 


\section{About the Authors}

Arkady Kryazhimskiy † was a Principal Research Scholar at the Steklov Institute of Mathematics of the Russian Academy of Sciences, Russia; a Professor at the Lomonosov Moscow State University, Faculty of Computational Mathematics and Cybernetics, Russia; and a Senior Research Scholar at the International Institute for Applied Systems Analysis, Austria. He was a Full Member of the Russian Academy of Sciences. His research interests included games theory, optimization, and ill-posed problems.

Elena Rovenskaya is Program Director of the Advanced Systems Analysis Program at the International Institute for Applied Systems Analysis; and a Research Scholar at the Lomonosov Moscow State University, Faculty of Computational Mathematics and Cybernetics, Russia. Her research interests include economic-environmental modeling and optimization.

Anatoly Shvidenko is a Senior Research Scholar at the International Institute for Applied Systems Analysis, Austria. His main fields of interest are forest inventory, monitoring, mathematical modeling, global change, and boreal forests. 


\title{
Towards harmonizing competing models: Russian forests' net primary production case study
}

\author{
Arkady Kryazhimskiy a,b,c Elena Rovenskaya ${ }^{\mathrm{a}, \mathrm{b}}$, Victoria Veshchinskaya ${ }^{\mathrm{a}}$, Mykola Gustia,e \\ Dmitry Shchepashchenko a,f and Anatoly Shvidenko ${ }^{\mathrm{a}, \mathrm{d}}$ \\ ${ }^{a}$ International Institute for Applied Systems Analysis, \\ Schlossplatz 1, A-2361, Laxenburg, Austria \\ ${ }^{b}$ Lomonosov Moscow State University, Faculty of Computational Mathematics and Cybernetics, \\ $2^{\text {nd }}$ Educational Building, Leninskie Gory, 119991, Moscow, Russia \\ c Steklov Mathematical Institute, 8 Gubkina str., 119991, Moscow, Russia \\ ' Sukachev Institute of Forest, Siberian Branch RAS, \\ Akademgorodok, 660036, Krasnoyarsk, Russia \\ ${ }^{e}$ Department of International Information, Lviv Polytechnic National University, \\ 12 Bandera str., 79013, Lviv, Ukraine \\ ${ }^{f}$ Moscow State Forest University, 1 Institutskaya str., 141005, Mytischi, Moscow region, Russia
}

\section{Introduction}

Complex socio-environmental systems are at the focus of systems analysis nowadays. Such systems are usually under-understood and are seen by researchers as fuzzy and highly uncertain. Due to a high complexity of the underlying process, any model designed to describe it, is bound to capture part of its critical elements and ignore the others. In the absence of formal procedures prescribing a modeller how to select "important" aspects to be included in the model, the modeller bases his/her choice on a mixture of theory, intuition, individual preferences and personal expertise. In this context, it is not surprising that in the half-a-century history of systems analysis competing models have been created to describe the same phenomena. As a rule, the modeling results for such systems cannot be verified/validated in a solid formal way (National Research Council, 2012). Known approaches to revealing the models' skills are based on assessment of the models' abilities to reproduce the past and the present states of the underlying systems; however, it has been reported that different assessment metrics may produce different, sometimes contradictory, results and, consequently, provide different rankings of the models (Gleckler et al., 2008). 
Uncertainty in ranking the models has, to some extent, motivated development of a multimodel approach in system analysis. Instead of aiming at constructing the "best" model, researchers tend more and more frequently to use multi-model ensembles. Climate change is the research field, in which recognition of the value of the use of the multi-model approach has pioneered. For example, the Fourth IPCC Report relies on the results of 23 global climate models (Randall et al., 2007) considering their means; for the Fifth IPCC Report, the IPCC Expert group developed recommendations on good practice in assessing multi-model climate projections and combining those with advanced statistical approaches (Knutti, 2010a).

Each model taken from a multi-model ensemble relies on its particular set of assumptions and modeling tools, and views the underlying phenomenon from a specific angle. Each model is usually attributed with its intrinsic uncertainties, often grouped into uncertainties in initial conditions, uncertainties in boundary conditions, parameter uncertainties and structural uncertainties (Tebaldi and Knutti, 2007). For that reason, each model's outcome is commonly represented as a random variable (or a random process). A systems analyst deals then with a family of probability distributions providing alternative descriptions to the same object.

In particular applications, researchers facing such phenomena employ specific features of the systems under investigation to reconcile alternative pieces of information and generate integrated knowledge (see, e.g., Nilsson et al., 2007). However, the subjectivity of the experts' experiences involved in such research efforts makes those research efforts vulnerable for criticism. Development of a well-justified tool for integration of different viewpoints into a single picture becomes a challenge in systems analysis.

There have been several impressive attempts undertaken to create a formal methodology for integration of alternative models-based results. To our knowledge, such attempts concentrate, primarily, on the question of weighting (in an appropriate way) results of the models that form a multi-model ensemble, based on assessment of the models' performance for the past and the present (Rajagopalan et al., 2002, Robertson et al., 2004, Tibaldi and Knutti, 2007); the weights may also incorporate information on the degree of the models' interdependence (see, e.g., Knutti, 2010b for an overview of currently available approaches). Knutti (2010a) pointing out serious difficulties in weighting the models, claims that "a robust approach to assigning weights to individual model projections of climate change has yet to be identified. ... Studies should employ formal statistical frameworks rather than using ad hoc techniques.” In this paper we present an illustrative example of a unified formal approach to posterior integration of prior random estimates (probability distributions) provided by independent statistically inaccurate observation methods.

Some attempts have been made to develop approaches to weighting models with no use of information on their performance in the past and the present. For example, Quegan et al. (2011) suggest weighting prior Gaussian estimates inverse proportionally to their variances within the Bayesian approach; this results in a posterior Gaussian estimate to which terms with higher uncertainty (variance) contribute less that those which are more certain. 
As opposed to the abovementioned techniques, Kryazhimskiy (2013) suggests an approach which does not employ the weighting paradigm and does not use information on the models' performance in the past and in the present. Therefore, it can be used in situations, where either the models' performance in the past and in the present is hard (or impossible) to estimate, or the future systems dynamics is anticipated to be radically different from that observed in the past and in the present. The core element of the methodology is the posterior event formed in the product of the probability spaces associated with the prior stochastic estimates. We use mutually compatible realizations of the prior random estimates to build a probability distribution on the posterior event. The Bayesian probability conditioned to the posterior event has identical projections onto the coordinate spaces; its common projection is defined to be the posterior integrated random estimate.

The illustrative case study presented in this paper focuses on assessment of the Net Primary Production (NPP) of the Russian terrestrial ecosystems. Along with heterotrophic respiration, the NPP represents the main flux of carbon exchange between ecosystems and the atmosphere and determines the degree of impact of vegetation on the global carbon budget. The NPP governed by climate and site conditions is an unbiased quantitative index of an ecosystem's response to climatic changes. Forests of the boreal zone (including Russia) represent one of the main stabilizing elements in the planetary climatic system functioning at high latitudes.

Due to a high complexity of the phenomenon, its intrinsic uncertainty, differences in the credibility of background information and diversification in methodologies, the existing estimates of the NPP of the Russian terrestrial ecosystems, obtained from different sources vary by more than $100 \%$ - from 204 to $614 \mathrm{~g} \mathrm{C} / \mathrm{m}^{2}$ per year (Bazilevich, 1993; Zamolodchikov and Utkin, 2000; Moiseev and Alyabina, 2007; Gower et al., 2001). Each of the estimation methods used has scientific and methodological advantages and disadvantages. In this paper we provide integrated estimates of the NPP of the Russian terrestrial ecosystems, which reconcile the estimates generated by two alternative methods.

The paper is organized as follows. In section 2 we briefly describe the integration methodology we use in our study. Section 3 supplies information on data of the NPP of the Russian terrestrial ecosystems specified for seven bio-climatic zones. Section 4 presents the results of integration of the NPP of the Russian terrestrial ecosystems for seven bio-climatic zones. In Section 5 we conclude and discuss.

\section{Methodology}

To reconcile (integrate) random estimates provided by alternative observation (modeling) methods, we use the methodology suggested by Kryazhimskiy (2013). The methodology is based on construction of a posterior event in the product of the probability spaces associated with the prior random estimates. A brief description of the methodology is as follows. Suppose an unknown element $\mathrm{z}^{0}$ of a finite set of elementary events, $Z$, is observed (modeled) using 
alternative independent observation (modeling) methods $1, \ldots, \mathrm{n}$. Each method, $i$, is inaccurate in a statistical sense, namely, method, $i$ describes $z^{0}$ as a probability distribution $\pi_{i}$ on $Z$. The probability distributions $\pi_{1}, \ldots, \pi_{\mathrm{n}}$ serve as prior random estimates for $\mathrm{z}^{0}$.We consider a posterior situation that occurs after the use of methods $1, \ldots, \mathrm{n}$. In the posterior situation elements $\mathrm{z}_{1}, \ldots, \mathrm{z}_{\mathrm{n}} \in \mathrm{Z}$ resulting from $\mathrm{n}$ independent random tests from methods $1, \ldots, \mathrm{n}$ are true if and only if $\mathrm{z}^{0}=\mathrm{z}_{1}=\ldots=\mathrm{z}_{\mathrm{n}}$. Since $\mathrm{z}^{0}$ is unknown, $\mathrm{z}_{1}=\ldots=\mathrm{z}_{\mathrm{n}}$ is a necessary posterior consistency condition in the product probability space $\left(\mathrm{Z}^{\mathrm{n}}, \mathrm{P}\right)=\left(\mathrm{Z}, \pi_{1}\right) \times \ldots \times\left(\mathrm{Z}, \pi_{\mathrm{n}}\right)$.. The posterior consistency condition determines a posterior event $\mathrm{E}_{*}=\left\{\left(\mathrm{z}_{1}, \ldots, \mathrm{z}_{\mathrm{n}}\right) \in \mathrm{Z}^{\mathrm{n}}: \mathrm{z}_{1}=. .=\mathrm{z}_{\mathrm{n}}\right\}=$ $\{(\mathrm{z}, \ldots, \mathrm{z}): \mathrm{z} \in \mathrm{Z}\}$ which is necessarily realized in $\left(\mathrm{Z}^{\mathrm{n}}, \mathrm{P}\right)$ in the posterior situation. We have

$$
\mathrm{P}\left(\mathrm{E}_{*}\right)=\sum_{\mathrm{z} \in \mathrm{Z}} \pi_{1}(\mathrm{z}) \ldots \pi_{\mathrm{n}}(\mathrm{z}) .
$$

If $\mathrm{P}\left(\mathrm{E}_{*}\right)=0$, methods $1, \ldots, \mathrm{n}$ are in contradiction in the sense that for every $\mathrm{z} \in \mathrm{Z}$ there is a method, $\mathrm{i}$, which evaluates the observed element $\mathrm{z}^{0}$ as $\mathrm{z}$ with a zero probability, $\pi_{\mathrm{i}}(\mathrm{z})=0$. Suppose $P\left(E_{*}\right)>0$, implying that methods $1, \ldots, n$ are not in contradiction in the sense that there exists a $\mathrm{z} \in \mathrm{Z}$ such that all the methods give non-zero probabilities for the fact that $\mathrm{z}^{0}=\mathrm{z}$. The Bayesian conditional probability distribution $\mathrm{P}\left(\cdot \mid \mathrm{E}_{*}\right)$ on $\mathrm{E}_{*}$ is given by

$$
P\left((z, \ldots, z) \mid E_{*}\right)=\frac{\pi_{1}(z) \ldots \pi_{n}(z)}{P\left(E_{*}\right)}
$$

for every $\mathrm{z} \in \mathrm{Z}$. We define a probability distribution $\pi_{1} \cdot \ldots \cdot \pi_{\mathrm{n}}$ on $\mathrm{Z}$ by setting

$$
\left(\pi_{1} \cdot \ldots \cdot \pi_{n}\right)(z)=P\left((z, \ldots, z) \mid E_{*}\right)
$$

for every $z \in Z$. In the probability space $\left(Z, \pi_{1} \cdot \ldots \cdot \pi_{n}\right)$ for every $z \in Z$ the probability of $z^{0}=z$ is proportional to $\pi_{1}(\mathrm{z}) \cdot \ldots \cdot \pi_{\mathrm{n}}(\mathrm{z})$ - the probability of the fact that all the methods admit that $\mathrm{z}^{0}=\mathrm{z}$. The latter probability is a measure of a 'consensus' of methods $1, \ldots, \mathrm{n}$ in conjecturing that $\mathrm{z}^{0}=\mathrm{z}$. All the methods contribute to the value of the 'consensus measure' $\pi_{1}(z) \cdot \ldots \cdot \pi_{n}(z)$ equally, and each method, i, has a 'power of veto' in the sense that the 'consensus measure' of $z$ vanishes if $\pi_{\mathrm{i}}(\mathrm{z})=0$. Thus, probability distribution $\pi_{1} \cdot \ldots \cdot \pi_{\mathrm{n}}$ provides an integrated knowledge on $\mathrm{z}^{0}$, which results from a posterior analysis of the use of methods $1, \ldots, \mathrm{n}$. According to Kryazhimskiy (2013), $\pi_{1} \cdot \ldots \cdot \pi_{n}$ is the posterior integrated random estimate resulting from the prior random estimates $\pi_{1}, \ldots, \pi_{n}$. The transformation of $\pi_{1}, \ldots, \pi_{n}$ into $\pi_{1} \cdot \ldots \cdot \pi_{n}$ is called integration of $\pi_{1}, \ldots, \pi_{n}$.

Often, the observed element is a real number. In that case, $\mathrm{Z}$ is a finite set of reals numbers, and every probability distribution, $\pi$, on $\mathrm{Z}$ describes a discrete random variable taking values in $\mathrm{Z}$. The variance of that random variable, $\mathrm{V}(\pi)$, is a standard measure of informativeness of $\pi$. If $V\left(\pi_{1} \cdot \ldots \cdot \pi_{n}\right)<V\left(\pi_{i}\right)$ for all $i=1, \ldots, n$, the posterior random estimate, $\pi_{1} \cdot \ldots \cdot \pi_{n}$, is more informative than every prior random estimate, $\pi_{i}$. A straightforward interpretation is that the prior random estimates enhance each other through integration and are therefore structurally compatible. If, conversely, $\mathrm{V}\left(\pi_{1} \cdot \ldots \cdot \pi_{\mathrm{n}}\right)>\mathrm{V}\left(\pi_{\mathrm{i}}\right)$ for all $\mathrm{i}=1, \ldots, \mathrm{n}$, the posterior random estimate, $\pi_{1} \cdot \ldots \cdot \pi_{n}$, is less informative than every prior random estimate, $\pi_{i}$. Then all the prior random estimates are structurally incompatible; consequently, some of them are misleading. In 
an intermediate situation, where $V\left(\pi_{i}\right)<V\left(\pi_{1} \cdot \ldots \cdot \pi_{n}\right)>V\left(\pi_{j}\right)$ for some $i$ and $j$, there is no clear agreement among the prior random estimates.

\section{Uncertainties in NPP estimates}

\subsection{NPP estimation methods and associated uncertainties}

Large uncertainties in estimates of the contribution of the terrestrial ecosystems to the global carbon cycle (see, e.g., Shvidenko et al. 2003, 2013) hinder scientific understanding of the problem of reduction of greenhouse gas emissions (see, e.g., Schulze 2002) and hamper political and economic decision making (see, e.g., Janssens et al. 2005). The full carbon account (FCA) approach (Shvidenko et al., 2010a,b) is aimed at providing a reliable and comprehensive (to a possible extent) account for carbon cycling uncertainties. The FCA evaluates spatial and temporal uncertainties in the complex fuzzy dynamic system of carbon cycling. The result of application of every specific CA method includes both a method-specific uncertainty and the structural, "true" uncertainty. The latter, however, is inseparable from the whole uncertainty, especially if the FCA is applied at a national or continental scale.

A natural way to extract "true" uncertainty and eliminate the influence of the method might be the use of several specific independent FCA methods, including their harmonization and identification of mutual constraints in intermediate and final estimates (Shvidenko et al., 2010a). Such kind of analysis requires a formal methodology for integrating uncertain estimates provided by either alternative carbon cycling assessment methods, or by alternative approaches to assessment of the ecosystems’ major biophysical indicators.

The NPP is among the most important forest ecosystems biophysical FCA indicators. Methods for estimating the terrestrial ecosystems' NPP include statistical methods based on direct in situ measurements; dynamic vegetation modes; ecophysiological carbon flow models; remote sensing methods; production efficiency models; and others. Each method has its advantages and shortcomings (Goetz, 1997; Mokronosov, 1999; Shvidenko et al., 2007b) and evaluates the NPP with uncertainty, which often results in a biased estimate. The sources of method-specific uncertainties include inconsistency of the background definition of the NPP and field measurements; a dynamic character of the NPP; oversimplification of the models used; problems with adequate descriptions of numerous interacting drivers; and many others.

Below we give short descriptions of two independent forest ecosystems NPP estimation methods - the landscape-ecosystem approach (LEA) and the ensemble of dynamic global vegetation models (DGVMs). In Section 4 we use NPP estimates provided by those two alternative methods to demonstrate the applicability of the model integration techniques presented in Section 2 in assessment of the NPP of the Russian forests as a promising approach to reconciling the results and their uncertainties obtained by different models in diverse ecological applications. 


\subsection{The landscape-ecosystem approach}

The landscape-ecosystem approach (LEA) suggests a methodology for aggregating empirical and semi-empirical methods for studying terrestrial ecosystems carbon cycling. The LEA postulates that, firstly, an ecosystem (understood as a set of vegetation-soil ensembles of various scales) is a primary unit for scientific descriptions, modeling efforts and interpretations, and, secondly, the processes of energy and matter exchange within ecosystems are strongly influenced by the properties of landscapes. The LEA accumulates all relevant empirical knowledge and all available semi-empirical aggregations for a region under investigation. It comprises groundbased quantitative descriptions of the regional ecosystems and landscapes - a multi-layer and multi-scale Integrated Land Information System (ILIS); remote sensing data; results of measurements of fluxes and concentrations of gas compositions in the atmosphere; ecological models of various types and scales; and auxiliary models. The ILIS includes a GIS hybrid-landcover (HLC) representation of a territory, and attributive databases (DB). The DBs include measurements in situ, numerous physical and socio-economic indicators, empirical and "semiempirical” aggregations, data from relevant surveys and inventories, etc. The HLC is developed based on a multi-sensor remote sensing concept and utilizes available reliable ground information. Detailed descriptions of the structure and features of the LEA and ILIS can be found in Schepaschenko et al., 2011 and Shvidenko et al., 2010a,b.

Within the LEA, forest ecosystems' NPP is estimated using the (presumably) unbiased method described in Shvidenko et al., 2007a. The method employs regionally distributed empirical growth and bio-productivity forest models and is based on modeling full productivity of the forest ecosystems' live biomass. The annual NPP is estimated for each one-square-km pixel based on data on the dominant species, age, site index and relative stocking of forest stands.

\subsection{Dynamic global vegetation models}

Dynamic global vegetation models (DGVMs) describe physiological and biogeochemical processes within ecosystems and play a substantial role in accounting NPP. In practice, DGVMs, in spite of a number of shortcomings (the use of aggregated vegetation classes, incomplete representations of disturbances, operation with 'potential vegetation', exclusion from consideration of some important vegetation classes, e.g., agriculture or wetlands, etc.) constitute the only tool for capturing the drivers of the ecosystems functioning.

Cramer et al. (1999) presented cross-comparison of the NPP estimates provided by 17 DGVMs combined in three groups: (a) satellite-based models whose variables are derived from remote sensing data, including CASA (Potter et al., 1993), GLO-PEM (Prince, 1991), SDBM (Knorr and Heiman, 1995), TURC (Ruimy et al., 1996), SIB2 (Sellers et al., 1996a,b); (b) models for assessment of biogeochemical fluxes, including HRBM (Esser and Lautenschlager, 1994), CENTURY (Parton et al., 1993), TEM (McGuire et al., 1995), CARAIB (Warnant et al., 
1994), FBM (Ludeke et al., 1994), PLAI (Plöchl and Cramer, 1995a,b), SILVAN (Kaduk and Heimann, 1996), BIOME-BGC (Running and Hunt, 1993), KGBM (Kergoat, 1998), and (c) models for assessment of seasonal biogeochemical fluxes and vegetation structures, including BIOME3 (Haxeltine and Prentice, 1996), DOLY (Woodward et al., 1995) and HYBRID (Friend et al., 1997). In the cross-comparison exercise, the models use standardized input data (climate, soil texture data and normalized difference vegetation index (NDVI) by $0.5^{\circ}$ grid at a monthly temporal resolution scale), being substantially different in definitions of the underlying NPP production processes. The models of group (a) work with the actual land covers; the models of group (b) use, primarily, predefined vegetation distributions based on available maps of potential vegetation; and models of group (c) determine the vegetation types and structures by maximizing the NPP at a regional basis under observed or predicted climate conditions. Four models (CASA, CENTURY, SDBM and HRBM) relate the NPP directly to vegetation characteristics temperature, solar radiation, precipitation, and others, while the remaining 13 ones represent the NPP as the difference between the gross primary production and autotrophic respiration. The modeled annual global NPP estimates turn out to be rather consistent across the models; although Cramer et al. (1999) state that additional calibration procedures may improve the degree of consistency.

For the terrestrial ecosystems limited to the territory of Russia all 17 models were used to estimate the NPP means and standard deviations (st.d.). The estimates were collected as explicit geographic data ${ }^{1}$; the data overlap with a bio-climatic zone (BCZ) map and forest areas represented in a land cover (LC) map for Russia (Schepaschenko et al., 2011). The estimates were aggregated under an assumption that the NPP estimates provided by every particular model were inter-dependent across the grid cells and the NPP estimates provided by different models were independent in every grid cell. For the BCZ and LC categories the aggregated NPP values were estimated as those averaged over the grid cells. The resulting aggregate estimates for the NPP annual means and standard deviations by the BCZs agree essentially. Within each BCZ the variability of the aggregate estimates of the NPP across the models ranged from 13 to 18\% slightly increasing towards the ecotones of the forest zone.

\subsection{Comparison of DGVMs- and LEA-based forest NPP estimates for Russia}

Table 1 compares the aggregate NPP means and standard deviations averaged over 17 DGVMs with those provided by the LEA. It should be noted that as only five DGVMs use information on the actual land covers (the other ones use information on potential vegetation), it is expected that the averaged DGVMs-based aggregate estimates for the NPP means exceed the LEA-based ones. Table 1 shows that this holds for the total NPP mean and for the NPP means in five of seven BCZs; exceptions are the forests in the tundra and steppe zones with limited areas of forests).

${ }^{1}$ http://islscp2.sesda.com/ISLSCP2_1/html_pages/groups/carbon/model_npp_xdeg.html 
While the LEA results do not have recognized biases, the DGVMs overestimate the "real" NPP; however, the degree of overestimation is relatively low.

\begin{tabular}{|c|c|c|c|c|c|c|}
\hline \multirow[b]{2}{*}{ BCZs } & \multicolumn{2}{|c|}{$\begin{array}{l}\text { DGVMs-based } \\
\text { estimates }\end{array}$} & \multicolumn{2}{|c|}{ LEA-based estimates } & \multicolumn{2}{|c|}{ Differences } \\
\hline & $\begin{array}{c}\text { mean } \\
\text { NPP, } \\
\text { g C/m² } \\
\text { per year }\end{array}$ & $\begin{array}{c}\text { st.d. } \\
\text { NPP, } \\
\text { g C/m² } \\
\text { per year }\end{array}$ & $\begin{array}{c}\text { mean } \\
\mathrm{NPP} \text {, } \\
\text { g C/m² } \\
\text { per year }\end{array}$ & $\begin{array}{c}\text { st.d. } \\
\text { NPP, } \\
\text { g C/m² } \\
\text { per year }\end{array}$ & $\begin{array}{c}\text { mean } \\
\mathrm{NPP} \text {, } \\
\text { g C/m² } \\
\text { per year }\end{array}$ & $\begin{array}{c}\text { mean } \\
\text { NPP, } \\
\%\end{array}$ \\
\hline Tundra & 202 & 36 & 225 & 89 & -23 & -11 \\
\hline $\begin{array}{l}\text { Forest tundra and Northern } \\
\text { taiga }\end{array}$ & 269 & 45 & 212 & 85 & +57 & +21 \\
\hline Middle taiga & 335 & 58 & 257 & 111 & +78 & +23 \\
\hline Southern taiga & 449 & 62 & 390 & 159 & +59 & +13 \\
\hline Temperate & 517 & 62 & 454 & 200 & +63 & +12 \\
\hline Steppe & 390 & 67 & 399 & 190 & -9 & -2 \\
\hline Semi-deserts and deserts & 423 & 56 & 360 & 182 & +63 & +15 \\
\hline Total & 348 & 48 & 282 & 141 & +66 & +19 \\
\hline
\end{tabular}

Table 1: Comparison of the DGVMs-based and LEA-based estimates of the Russian terrestrial ecosystems’ NPP.

\section{Results}

\subsection{Data processing}

The full LEA-based data sets provide frequencies (further interpreted as probabilities) of the forests' observed NPP values ranging from 35 to $1365 \mathrm{~g} \mathrm{C} / \mathrm{m}^{2}$ per year for seven bioclimatic zones in Russia. Due to observation errors, processing errors, and spatio-temporal heterogeneities, the frequencies viewed as probability distributions are highly irregular (see the left column in Table 2). To smooth out the distributions, we aggregate the original data into size classes. We consider two size classes -10 and $90 \mathrm{~g} \mathrm{C} / \mathrm{m}^{2}$ per year.

The DGVM-based data sets suggest estimates for the forests' NPP means and standard deviations for the same seven bioclimatic zones in Russia. Based on those estimates, we reconstruct Gaussian distributions to accommodate for the entire NPP ranges. 


\subsection{Integration results}

We apply the methodology described in Section 2 to integrate, posteriorly, pairwise, (i) the original LEA-based and DGVMs-based Russian forests' NPP distributions; (ii) the LEA-based and DGVMs-based Russian forests’ NPP distributions aggregated into size classes of $10 \mathrm{~g} \mathrm{C} / \mathrm{m}^{2}$ per year; and (iii) the LEA-based and DGVMs-based Russian forests' NPP distributions aggregated into size classes of $90 \mathrm{~g} \mathrm{C} / \mathrm{m}^{2}$ per year. Table 2 shows the LEA-based and DGVMsbased forest ecosystem NPP distributions and the integrated posterior forest ecosystems NPP distributions for the BCZs in Russia in cases (i), (ii) and (iii). Tables 3a, 3b and 3c summarize statistics on the NPP means and standard deviations of the LEA-based distributions, DGVMsbased distributions and the corresponding integrated posterior distributions in cases (i), (ii) and (iii), respectively. Tables 3a, 3b and 3c show that in all cases and for all BCZs, the variances of the integrated posterior distibutions are smaller than those of the LEA-based and DGVMsbased distributions with two exceptions being cases (i) and (ii) for the semi-deserts and deserts BCZ; case (iii) for semi-deserts and deserts BCZ demonstrates a boundary situation in which the variance of the integrated distribution equals the minimum of those of the LEA-based and DGVMs-based ones.

Following the approach presented in Section 2, we conclude that the integrated posterior distributions improve both the prior LEA-based and DGVMs-based Russian forests' NPP estimates for three cases of data aggregation and for all bioclimatic zones, with the exception of the semi-deserts and deserts zone, for which a valid estimate is obtained only for the size class of $90 \mathrm{~g} \mathrm{C} / \mathrm{m}^{2}$ per year. 


\begin{tabular}{|c|c|c|c|}
\hline BCZs & Original NPP data & $\begin{array}{l}\text { NPP data aggregated into size } \\
\text { classes of } 10 \mathrm{~g} \mathrm{C} / \mathrm{m}^{2} \text { per year }\end{array}$ & $\begin{array}{l}\text { NPP data aggregated into size } \\
\text { classes of } 90 \mathrm{~g} \mathrm{C} / \mathrm{m}^{2} \text { per year }\end{array}$ \\
\hline Tundra & 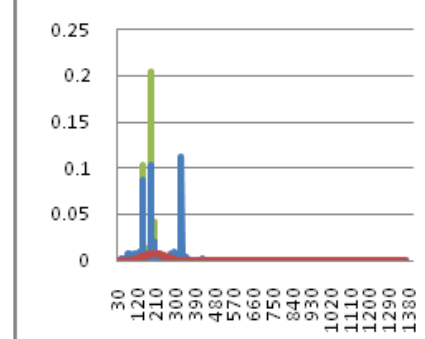 & 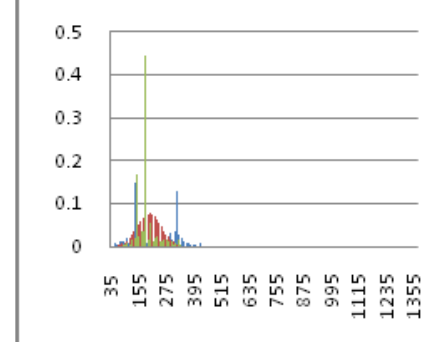 & 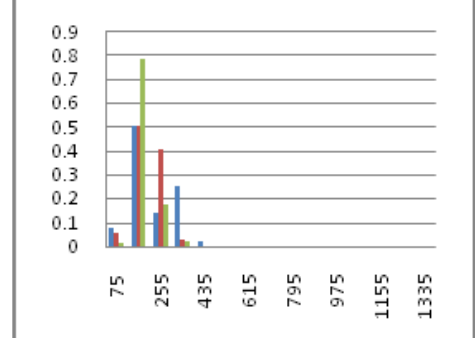 \\
\hline $\begin{array}{l}\text { Forest } \\
\text { tundra and } \\
\text { Northern } \\
\text { taiga }\end{array}$ & 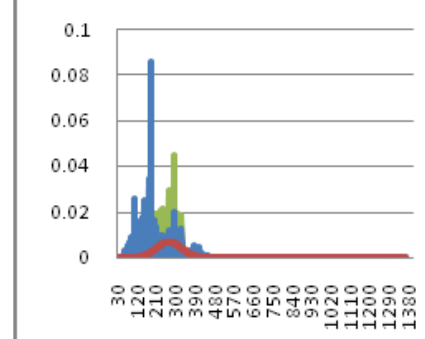 & 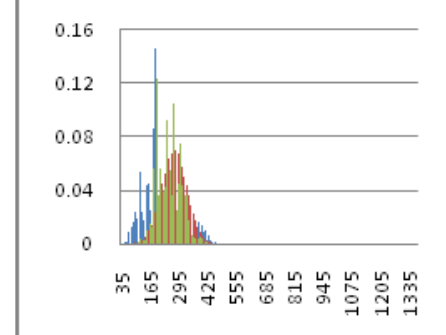 & 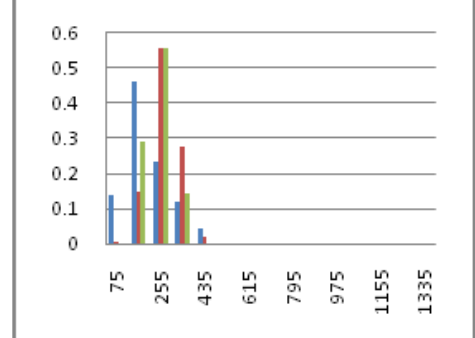 \\
\hline $\begin{array}{l}\text { Middle } \\
\text { taiga }\end{array}$ & 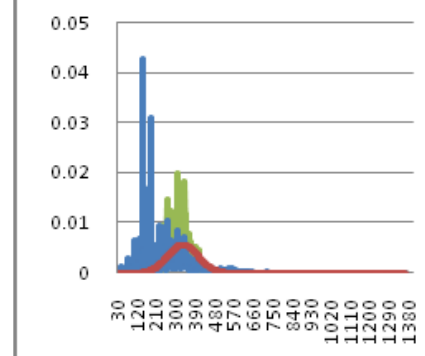 & 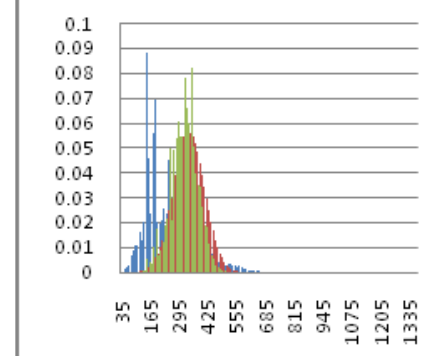 & 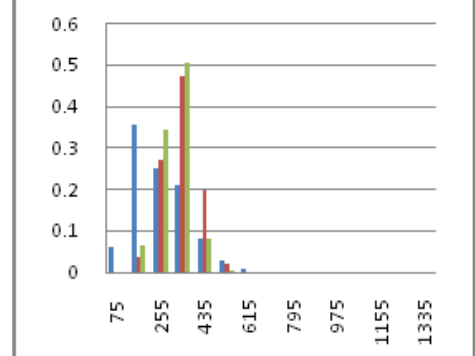 \\
\hline $\begin{array}{l}\text { Southern } \\
\text { taiga }\end{array}$ & 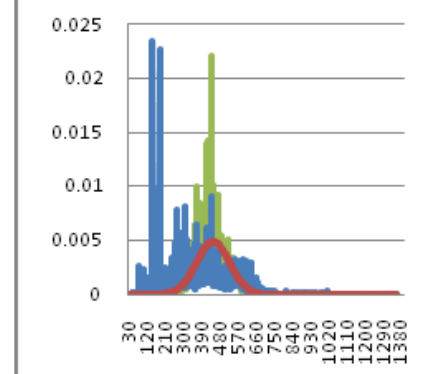 & 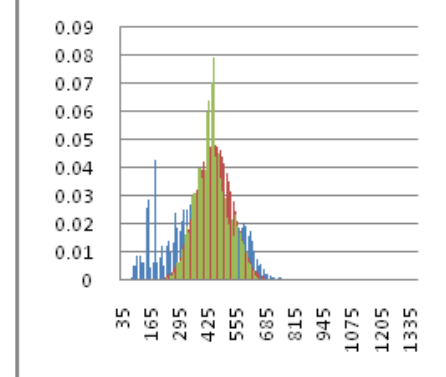 & 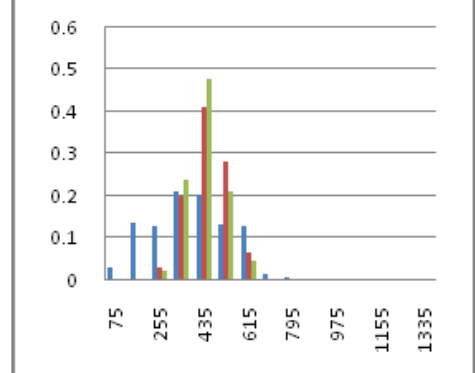 \\
\hline $\begin{array}{l}\text { Temperate } \\
\text { forests }\end{array}$ & 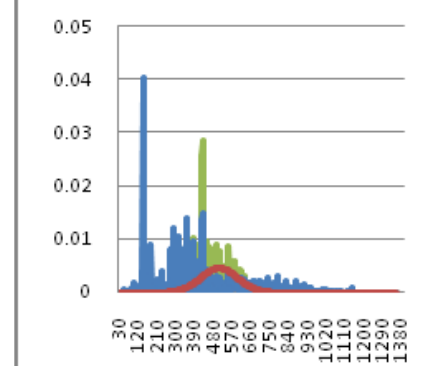 & 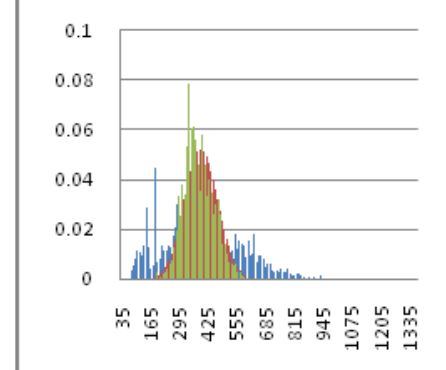 & 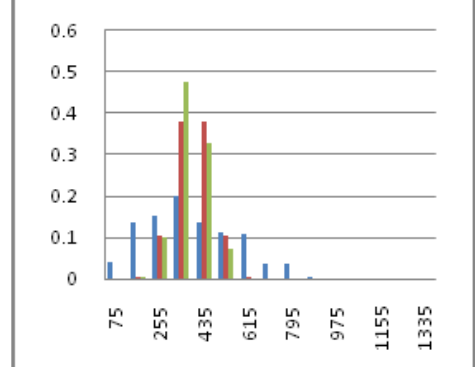 \\
\hline
\end{tabular}




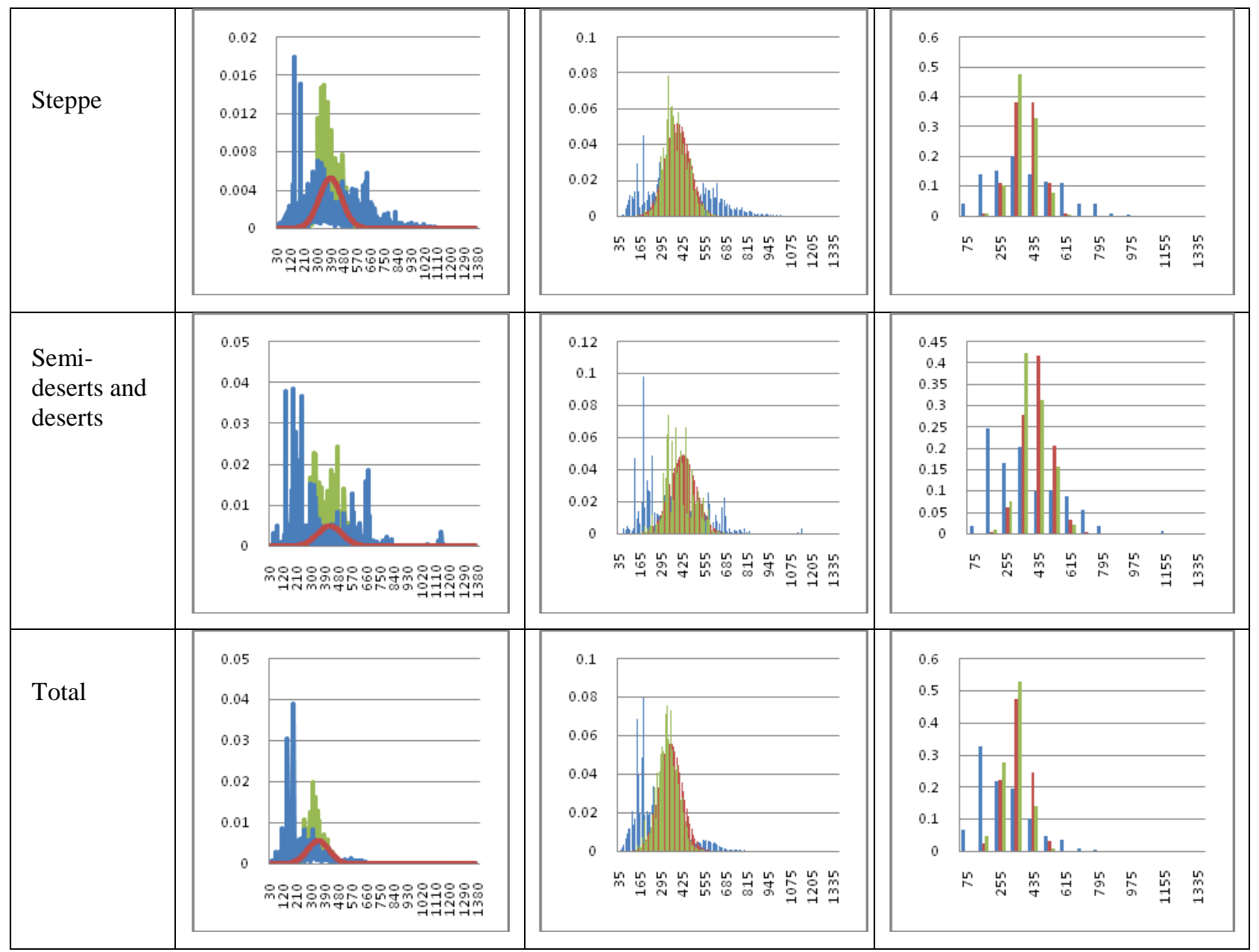

Table 2: The LEA-based distributions (blue), DGVMs-based distributions (red) and integrated posterior distributions (green) of the forest NPP estimates for Russia. The horizontal axis represents NPP values in $\mathrm{g} \mathrm{C} / \mathrm{m}^{2}$ per year, and the vertical axis represents frequencies (probabilities). 


\begin{tabular}{|l|c|c|c|c|c|c|}
\hline \multirow{2}{*}{ BCZs } & \multicolumn{2}{|c|}{$\begin{array}{c}\text { DGVMs-based } \\
\text { estimates }\end{array}$} & \multicolumn{2}{c|}{ LEA-based estimates } & \multicolumn{2}{c|}{ Integrated estimates } \\
\cline { 2 - 7 } & $\begin{array}{c}\text { mean NPP, } \\
\text { g C/m² } \\
\text { per year }\end{array}$ & $\begin{array}{c}\text { st.d. NPP, } \\
\text { g C/m² } \\
\text { year }\end{array}$ & $\begin{array}{c}\text { mean NPP, } \\
\text { g C/m² } \\
\text { per year } \\
\text { st.d. NPP, } \\
\text { g C/m² } \\
\text { per year }\end{array}$ & $\begin{array}{c}\text { mean } \\
\text { NPP, } \\
\text { g C/m² } \\
\text { per year }\end{array}$ & $\begin{array}{c}\text { st.d. NPP, } \\
\text { g C/m² } \\
\text { per year }\end{array}$ \\
\hline Tundra & 202 & 52 & 225 & 89 & 189 & 43 \\
\hline $\begin{array}{l}\text { Forest tundra and Northern } \\
\text { taiga }\end{array}$ & 269 & 57 & 212 & 85 & 245 & 54 \\
\hline Middle taiga & 335 & 70 & 257 & 111 & 312 & 62 \\
\hline Southern taiga & 449 & 82 & 390 & 159 & 438 & 76 \\
\hline Temperate & 313 & 87 & 454 & 200 & 492 & 85 \\
\hline Steppe & 423 & 81 & 360 & 182 & 403 & $86{ }^{*}$ \\
\hline Semi-deserts and deserts & 348 & 71 & 282 & 141 & 327 & 65 \\
\hline Total & 390 & 399 & 190 & 378 & 72 \\
\hline
\end{tabular}

Table 3a (case (i)): The original LEA-based and DGVMs-based and integrated posterior estimates of the forest NPP mean values and standard deviations for Russia. The upper star index marks the exceptional situation where the variance of the integrated posterior distribution is bigger than one of the LEA-based and DGVMs-based distributions.

\begin{tabular}{|l|c|c|c|c|c|c|}
\hline \multirow{2}{*}{ BCZs } & \multicolumn{2}{|c|}{$\begin{array}{c}\text { DGVMs-based } \\
\text { estimates }\end{array}$} & \multicolumn{2}{c|}{ LEA-based estimates } & \multicolumn{2}{c|}{ Integrated estimates } \\
\cline { 2 - 7 } & $\begin{array}{c}\text { mean NPP, } \\
\text { g C/m² } \\
\text { per year }\end{array}$ & $\begin{array}{c}\text { st.d. NPP, } \\
\text { g C/m² per } \\
\text { year }\end{array}$ & $\begin{array}{c}\text { mean NPP, } \\
\text { g C/m² } \\
\text { per year }\end{array}$ & $\begin{array}{c}\text { st.d. NPP, } \\
\text { g C/m² } \\
\text { per year }\end{array}$ & $\begin{array}{c}\text { mean } \\
\text { NPP, } \\
\text { g C/m² } \\
\text { per year }\end{array}$ & $\begin{array}{c}\text { st.d. NPP, } \\
\text { g C/m² } \\
\text { per year }\end{array}$ \\
\hline Tundra & 202 & 52 & 224 & 90 & 188 & 43 \\
\hline $\begin{array}{l}\text { Forest tundra and Northern } \\
\text { taiga }\end{array}$ & 269 & 57 & 213 & 85 & 244 & 54 \\
\hline Middle taiga & 335 & 70 & 257 & 111 & 312 & 62 \\
\hline Southern taiga & 449 & 82 & 390 & 159 & 438 & 76 \\
\hline Temperate & 513 & 87 & 455 & 201 & 491 & 85 \\
\hline Steppe & 390 & 76 & 400 & 190 & 377 & 72 \\
\hline Semi-deserts and deserts & 423 & 81 & 360 & 183 & 402 & $85^{*}$ \\
\hline Total & 348 & 71 & 282 & 141 & 327 & 65 \\
\hline
\end{tabular}

Table 3b (case (ii)): The LEA-based and DGVMs-based aggregated into size classes of $10 \mathrm{~g} \mathrm{C} / \mathrm{m}^{2}$ per year and the corresponding integrated posterior estimates of the forest NPP mean values and standard deviations for Russia. The upper star index marks the exceptional situation where the variance of the integrated posterior distribution is bigger than one of the LEA-based and DGVMs-based distributions. 


\begin{tabular}{|l|c|c|c|c|c|c|}
\hline \multirow{4}{*}{ BCZs } & \multicolumn{2}{|c|}{$\begin{array}{c}\text { DGVMs-based } \\
\text { estimates }\end{array}$} & \multicolumn{2}{c|}{ LEA-based estimates } & \multicolumn{2}{c|}{ Integrated estimates } \\
\cline { 2 - 7 } & $\begin{array}{c}\text { mean NPP, } \\
\text { g C/m² } \\
\text { per year }\end{array}$ & $\begin{array}{c}\text { st.d. NPP, } \\
\text { g C/m } \mathrm{m}^{2} \text { per } \\
\text { year }\end{array}$ & $\begin{array}{c}\text { mean NPP, } \\
\text { g C/m² } \\
\text { per year }\end{array}$ & $\begin{array}{c}\text { st.d. NPP, } \\
\text { g C/m² } \\
\text { per year }\end{array}$ & $\begin{array}{c}\text { mean } \\
\text { NPP, } \\
\text { g C/m² } \\
\text { per year }\end{array}$ & $\begin{array}{c}\text { st.d. NPP, } \\
\text { g C/m² } \\
\text { per year }\end{array}$ \\
\hline Tundra & 202 & 58 & 224 & 94 & 184 & 44 \\
\hline $\begin{array}{l}\text { Forest tundra and Northern } \\
\text { taiga }\end{array}$ & 269 & 63 & 208 & 93 & 242 & 59 \\
\hline Middle taiga & 335 & 75 & 258 & 114 & 310 & 66 \\
\hline Southern taiga & 449 & 86 & 390 & 162 & 437 & 78 \\
\hline Temperate & 513 & 91 & 456 & 205 & 490 & 86 \\
\hline Steppe & 390 & 80 & 400 & 194 & 380 & 74 \\
\hline Semi-deserts and deserts & 348 & 76 & 282 & 144 & 326 & 69 \\
\hline Total & & & & & & 85 \\
\hline
\end{tabular}

Table 3c (case (iii)): The LEA-based and DGVMs-based aggregated into size classes of $90 \mathrm{~g} \mathrm{C} / \mathrm{m}^{2}$ per year and the corresponding integrated posterior estimates of the forest NPP mean values and standard deviations for Russia.

\section{Discussion and conclusions}

In this paper, we demonstrated an application of a theoretical approach to posterior integration of alternative prior stochastic models of an unknown "true" biophysical indicator of ecosystems. Our study focused on posterior integration of the estimated frequency (probability) distributions of NPP values for the Russian terrestrial ecosystems, which resulted from two alternative prior NPP estimation methods - the landscape-ecosystem approach (LEA) and the ensemble of dynamic global vegetation models (DGVMs). The original LEA-based and DGVMs-based data and size-aggregated LEA-based and DGVMs-based data were integrated pairwise into a posterior distribution for each of the seven bioclimatic zones.

Although the mean zonal LEA-based and DGVMs-based NPP estimates differ for up to 23\%, we find out that for the majority of the bioclimatic zones, firstly, the LEA and DGVMs approaches are structurally compatible and, secondly, the integrated posterior NPP estimates are more credible (namely, have lower variations) than both the prior LEA-based and DGVMs-based ones. For every bioclimatic zone, in each of cases (i), (ii) and (iii), the variance of the DGVMsbased NPP distribution is lower than that of the LEA-based one. 
The LEA-based and DGVMs-based data underestimate and, respectively, overestimate the integrated estimates of the NPP means for all bioclimatic zones, except for tundra, for which the integrated estimate for the NPP mean is smaller than both the LEA-based and the DGVMs-based ones.

Posterior integration with the DGVMs-based data adjusts the LEA-based data significantly; for example, the LEA-based estimate of the total NPP mean grows, thanks to posterior integration with the DGVMs-based data, by approximately $16 \%$ in each case. Posterior integration with the LEA-based data adjusts the DGVMs-based data less strongly; for example, the DGVMs-based estimate of the total NPP mean decreases, thanks to posterior integration with the LEA-based data, by approximately $6 \%$ in each case.

This example illustrates an additional field of potential applications of the posterior integration method. If one of available estimates is considered as "true" (much more certain than the others), one can use posterior integration to assess applicability of other stochastic estimation methods more preferable in practical aspects (e.g., requiring the minimum amount of resources in practical implementation).

We conclude by stating that the approach presented here is applicable in cases where two or more stochastic estimates are used to describe a real quantity, while errors embedded in these estimates cause gaps between them and all prior estimates are equally likely to describe an unknown "true" indicator. Further development of this approach is seen in the direction of including amounts of information associated with each prior estimate that would differentiate contributions of those to a posterior integration based on some principles. 


\section{References}

Bazilevich, N.I. (1993). Biological productivity of ecosystems in Northern Eurasia, Nauka, Moscow, Russia, [in Russian].

Cramer, W., Kicklighter, D.W., Bondeau, A., Moore, B., Churkina, G., Nemry, B., Ruimy, A., Schloss, A.L., and the Participants of the Potsdam NPP Model Intercomparison Comparing Global Models of Terrestrial Net Primary Productivity (NPP) (1999). Overview and Key Results, Global Change Biology, 5(S1) 115.

Esser, G., and Lauenschlager, M. (1994). Estimating the change of carbon in the terrestrial biosphere from 1800 BP to present using a carbon cycle model, Environmental Pollution, 83 (4553.

Friend, A.D., Stevens, A.K., Knox, R.G., and Cannell, M.G.R. (1997). A processed-based, terrestrial biosphere model of ecosystem dynamics (Hybrid v.3.0), Ecological Modelling, 95 (23), 249-287.

Gleckler, P.J., Taylor, K.E., and Doutriaux C. (2008). Performance metrics for climate models, Journal of Geophysical Research, 113, D06104.

Goetz, S.J. (1997). Modeling carbon fluxes, net primary production, and light utilization in boreal forest stands, University of Maryland Press.

Gower, S.T., Krankina O., Olson, R.J., Apps, M., Linder, S., Wang, C. (2001). Net primary production and carbon allocation patterns of boreal forest ecosystems, Ecological Application , 11, 1395-1408.

Haxeltine, A., and Prentice, I. (1996). BIOME3: an equilibrium biosphere model based on ecophysiological constraints, resource availability and competition among plant functional types, Global Biogeochemical Cycles, 10, 119-140.

Janssens, I.A., Fribauer, A., Schlamadinger, B., Ceulemans, R., Ciais, P., Dolman, A.J., Heimann, M., Nabuurs, G.-J., Smith, P., Valentini, R., Schulze, E.-D. (2005). The carbon budget of terrestrial ecosystems at country-scale - A European Case Study, Biogeosciences, 2(1), 15-26.

Kaduk, J., and Heimann, M. (1996). A prognostic phenologe scheme for global terrestrial carbon cycle models, Climate Research, 6, 1-19.

Kergoat, L. (1998). A model for hydrological equilibrium of leaf area index on a global scale, Journal of Hydrology, 212-213, 268-286.

Knorr, W., and Heimann, M. (1995). Impact of drought stress and other factors on seasonal land biosphere CO2, Exchange studied through the Atmospheric Tracer Transport Model, 47, 471489. 
Knutti, R., Abramowitz, G., Collins, M., Eyring, V., Gleckler, P.J., Hewitson, B., Mearns, L. (2010a). Good practice guidance paper on assessing and combining multi-model climate projections, in: T.F.Stocker, D.Qin, G.-K.Plattner, M.Tignor, P.M.Midgley (Eds.), Meeting Report of the Intergovernmental Panel on Climate Change Expert Meeting on Assessing and Combining Multi Model Climate Projections, IPCC Working Group I Technical Support Unit, University of Bern, Bern, Switzerland.

Knutti, R., Furrer, R., Tebaldi, C., Cermak, J., Meehl, G.A. (2010b). Challenges in combining projections from multiple models, Journal of Climate, 23, 2739-2756.

Kryazhimskiy, A. (2013). Posterior integration of independent stochastic estimates, IIASA Interim Report IR-13-006. http://webarchive.iiasa.ac.at/Admin/PUB/Documents/IR-13-006.pdf

Ludeke, M., Badeck, F., Otto, R. (1994). The Frankfurt biosphere model. A global process oriented model for the seasonal and long-term CO2 exchange between terrestrial ecosystems and the atmosphere. I. Model description and illustrative results for cold deciduous and boreal forests, Climate Research, 4, 143-166.

McGuire, A., Melillo, J., Kicklighter, D. (1995). Equilibrium responses of soil carbon to climate change - empirical and process-based estimates. Journal of Biogeography, 22, 785-796.

Moiseev, B.N., and Alyabina, I.O. (2007). Assessment and mapping of components of carbon and nitrogen balances in major biomes of Russia, Proceedings of the Russian Academy of Sciences, Geography, 5, 1-15, [In Russian].

Mokronosov, A.T. (1999). Global photosynthesis and plant biodiversity. In: Carbon turnover in territories of Russia. Moscow, Russian Academy of Sciences, 19-62, [in Russian].

National Research Council. (2012). Assessing the reliability of complex models: mathematical and statistical foundations of verification, validation, and uncertainty quantification, The National Academies Press, Washington, DC, USA.

Nilsson, S., Shvidenko, A., Jonas, M., McCallum, I., Thompson, A., Balzter, H. (2007). Uncertainties of a regional terrestrial biota full carbon account: a system analysis, in: Accounting for Climate Change, Uncertainty in Greenhouse Gas Inventories - Verification, Compliance, and Trading, Springer, Netherlands.

Parton, W., Scurlock, J., Ojima, D. (1993). Observations and modelling of biomass and soil organic matter dynamics for the grassland biome worldwide, Global Biogeochemical Cycles, 7, 785-809.

Plöchl, M., and Cramer, W. (1995a). Coupling global models of vegetation structure and ecosystem processes, Tellus, 47B, 240-250. 
Plöchl, M., and Cramer, W. (1995b). Possible impacts of global warming on tundra and boreal ecosystems - comparison of some biogeochemical models. Journal of Biogeography, 22, 775784.

Potter, C.S., Randerson, J.T., Field, C.B., Matson, P.A., Vitousek, P.M., Mooney, H.A., Klooster, S.A. (1993). Terrestrial ecosystem production: a process model based on global satellite and surface dataGlob. Biogeochem. Cycles, 7 (4), 811-841.

Prince, S. (1991). A model of regional primary production for use with coarse-resolution satellite data, International Journal of Remote Sensing, 12, 1313-1330.

Quegan, S., Beer, C., Shvidenko, A., McCallum, I., Handoh, I.C., Peylin, P., Roedenbeck, C., Lucht, W., Nilsson, S., Schmullius, C. (2011). Estimating the carbon balance of central Siberia using landscape-ecosystem approach, atmospheric inversion and Dynamic Global Vegetation Models, Global Change Biology, 17, 351-365.

Rajagopalan, B., Lall, U., Zebiak, S.E. (2002). Categorical climate forecasts through regularization and optimal combination of multiple GCM ensembles, Monthly Weather Review, 130, 1792-1811.

Randall, D.A., Wood, R.A., Bony, S., Colman, R., Fichefet, T., Fyfe, J., Kattsov, V., Pitman, A., Shukla, J., Srinivasan, J., Stouffer, R.J., Sumiand, A., Taylor, K.E. (2007). Climate models and their evaluation, in: S.Solomon, D.Qin, M.Manning, Z.Chen, M.Marquis, K.B.Averyt, M.Tignor, H.L.Miller, Climate Change 2007: The Physical Science Basis. Contribution of Working Group I to the Fourth Assessment Report of the Intergovernmental Panel on Climate Change, Cambridge University Press, Cambridge, UK and New York, NY, USA.

Robertson, A.W., Lall, U., Zebiak, S.E., Goddard, L. (2004). Improved combination of multiple atmospheric GCM ensembles for seasonal prediction, Monthly Weather Review, 132, 27322744.

Ruimy, A., Dedieu, G., Saugier, B. (1996). TURC: a diagnostic model of continental gross primary productivity and net primary productivity, Global Biogeochemical Cycles, 10, 269-286.

Running, S.W., and Hunt, E.R. (1993). Generalization of a forest ecosystem process model for other biomes, BIOME-BGC and an application for global-scale models, in: J.Eheleringer, C.Field (Eds.) Scaling Physiological Processes: Leaf to Globe, Academic Press, San Diego, USA.

Schepaschenko, D.G., McCallum, I., Shvidenko, A., Fritz, S., Kraxner, F., Obersteiner, M. (2011). A new hybrid land cover dataset for Russia: a methodology for integrating statistics, remote sensing and in-situ measurements, Journal of Land Use Science, 6, 245-259. 
Schulze, E.D. (2002). Understanding global change: lessons learnt from the European landscape, Journal of Vegetation Science, 13, 403-412.

Sellers, P., Randall, D., Gollatz, G. (1996a). A revised land surface parametrization (SiB2) for atmospheric GCMs. Part I: Model formulation, Journal of Climate, 9, 676-705.

Sellers, P., Compton, J., Tucker, G., Gollatz, G., Los, S., Justice, C., Dazlich, D., Randall, D. (1996b). A revised land surface parametrization (SiB2) for atmospheric GCMs. Part II: The generation of global fields of terrestrial biophysical parameters from satellite data, Journal of Climate, 9, 706- 737.

Shvidenko, A., and Nilsson, S. (2002). A synthesis of the impact of Russian forests on the global carbon budget for 1961-1998, Tellus B, 55, 391-415.

Shvidenko, A., Schepaschenko, D., Nilsson, S., Bouloi, Y. (2007a). Semi-empirical models for assessing biological productivity of Northern Eurasian forests, Ecological Modelling, 204, 163179.

Shvidenko, A.Z., Schepaschenko, D.G., Nilsson, S. (2007b). Materials for understanding of the present-day productivity of forest ecosystems of Russia, in: V.A.Sokolov, A.Z.Shvidenko, O.P.Vtyurina (Eds.) Basic Problems of Transition to Sustainable Forest Management in Russia, Sukachev Institute of Forest, SB RAS, Krasnoyarsk, Russia, [in Russian].

Shvidenko, A., Schepaschenko, D., McCallum, I., Nilsson, S. (2010a). Can the uncertainty of full carbon accounting of forest ecosystems be made acceptable to policy makers? Climatic Change, 103, (1-2), 137-157.

Shvidenko, A., Schepaschenko, D., Maksyutov, S. (2010b). Impact of terrestrial ecosystems of Russia on the global carbon cycle for 2003-2008: An attempt of synthesis. Proceedings of the International Conference ENVIROMIS-2010, 5-10 July 2010, Tomsk, Russia, 48-52.

Shvidenko, A., Kraxner, F., Obersteiner, M., Schepaschenko, D. (2013). Terrestrial ecosystems full carbon account as a fuzzy system: An attempt to understand uncertainties, Plenary presentation at the $9^{\text {th }}$ International CO2 Conference, 3-7 June 2013, Beijing, China.

Tebaldi, C., and Knutti, R. (2007). The use of the multi-model ensemble in probabilistic climate projections, Philosophical Transactions of the Royal Society, A, 365, 2053-2075.

Warnant, P., Francois, L., Strivay, D., Gerard, J. (1994). CARAIB: a global model of terrestrial biological productivity, Global Biogeochemical Cycles, 8, 225-270.

Woodward, F.I., Smith, T.M., Emanual, W.R. (1995). A global land primary productivity and phytogeography model, Global Biogeochemical Cycles, 9, 471-490. 
Zamolodchikov, D.G., and Utkin, A.I. (2000). System of conversion relations for calculating the net primary production of forest ecosystems from tree stocks, Lesovedenie, 6, 54-63, [In Russian]. 